\title{
BILATERAL AND MULTIFOCAL WARTHIN'S TUMOR OF PAROTID GLAND: TWO CASE REPORTS AND REVIEW OF LITERATURE
}

\author{
G. NICOLAI ${ }^{1}$, E. VENTUCCI ${ }^{1}$, P. ANTONUCCI ${ }^{1}$, V. COSTANTINO ${ }^{1}$, G. BRUNELLI ${ }^{2}$, \\ G. MARIANI ${ }^{1}$, A. SALTAREL ${ }^{1}$, B. LORE ${ }^{1}$, L. CALABRESE $^{1}$
}

${ }^{1}$ Department of Oral and Maxillo-Facial Surgery, University of Rome "Tor Vergata”, Rome, Italy

${ }^{2}$ Department of Odontostomatologic Clinic, University of Cagliari, Cagliari, Italy

\begin{abstract}
SUMMARY
Warthin's tumor is the second most common benign neoplasm of the parotid. Most of cases are represented by a single localization, while only a small percentage of patients presents bilateral lesions or unilateral multifocal pattern. Warthin's tumor has an excellent prognosis due to the low rate of recurrence after surgical treatment. Malignant transformation occurs in less than $1 \%$ of cases. The aim of this article is to present two unusual cases of Warthin's tumor and an updated review of the latest scientific literature.
\end{abstract}

Key words: Warthin's tumor, major salivary glands neoplasm, parotid benign neoplasm, multifocal lesions, bilateral lesions, parotidectomy.

\section{Introduction}

Warthin's tumor is one of the most common benign neoplastic diseases of major salivary glands, second for frequency only to pleomorphic adenoma $(1,2)$. It has been described for the first time at the end of IX century and the histological features led to the development of several classifications. Currently most used nomenclature is the eponym classification that refers to the pathologist who contributed to the characterization of this histological entity. This lesion frequently affects the elderly, and has a close correlation with smoking habits (3-5). In the past, there was a high prevalence in males, but recent studies have shown a strong growth rate for the female sex, probably due to the rising prevalence of smoking habits among women (6-8). The tumor is characterized by a mass localized in the lower pole of the parotid gland. Warthin's tumor is histologically benign and malignant evolution is very rare. The surgical eradication is often needed because of the tendency of the mass to growth up until the achievement of significant size. The aim of this article is to provide a description of two peculiar and rare clinical cases because of the bilateral and multifocal features of the lesions, as well to provide a current review of the most relevant literature.

\section{Case series}

\section{Case 1}

A 50-year-old man was referred to the Oral and Maxillo-Facial Surgery Department of Tor Vergata Policlinic, with an 8-month-history of swelling of the left parotid region. Physical examination revealed a well-circumscribed mass in the inferior portion of the left parotid gland nearby the mandibular angle. On palpation, the swelling was not painful and showed a non-tender consistency. 
It was movable to the deeper tissue and to superficial skin that was otherwise normal for color and appearance. Moreover, palpation disclosed a second mass, more deep than the first one, located under the left auricular lobe. This second swelling revealed to be movable on deep and superficial tissues. Intra-oral examination showed a good healthy status of mucosae. Facial nerve function was normal. On anamnesis, the patient confirmed to be a smoker with a consumption of about 20 cigarettes a day. No other relevant pathologies were reported on the medical history. A MRI with and without contrast enhancement was performed with axial, coronal and sagittal scans. It showed two solid masses with not- homogeneous appearance into the parotid parenchyma (Figs. 1,2). One located in para-pharyngeal prolongation with the greatest diameter of $23 \mathrm{~mm}$. The second one with

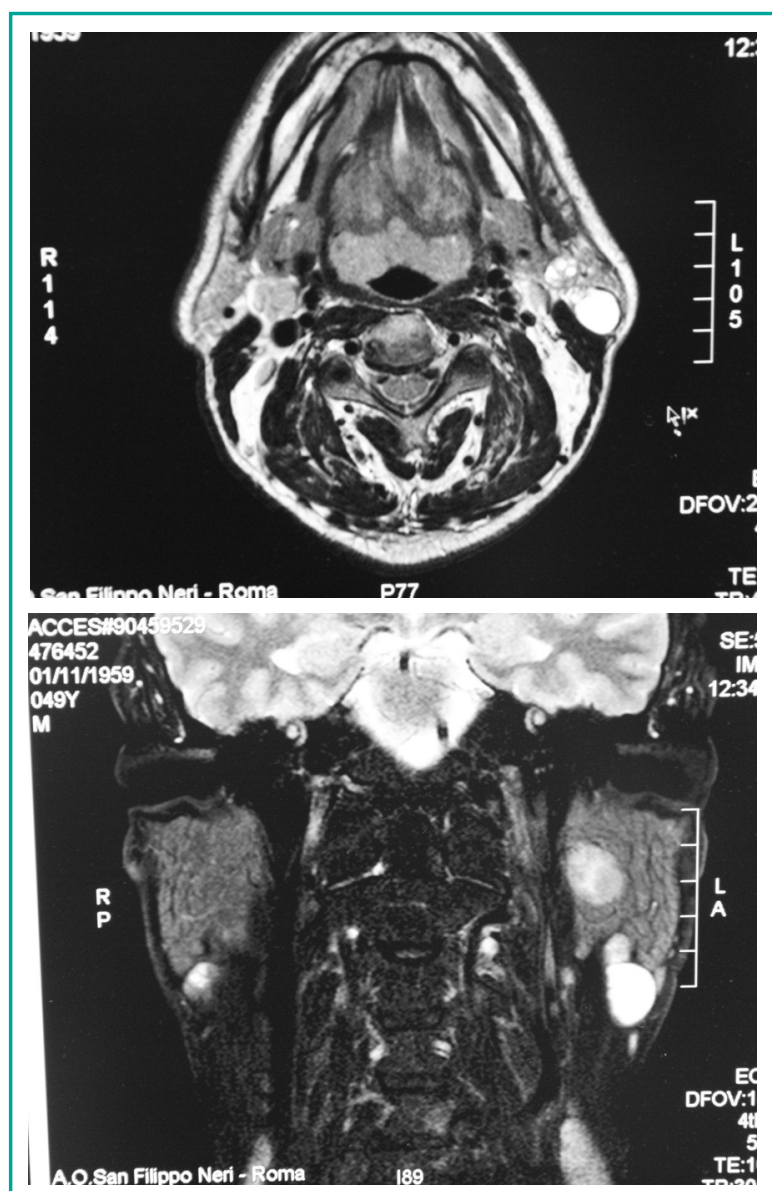

Figures 1, 2 - Picture of axial and coronal view of MRI showing two masses in the left parotid gland. the greatest diameter of $17 \mathrm{~mm}$ was located in the inferior pole of the gland. No increased dimension or with pathological features lymph nodes were found in sub-mandibular area neither in lateralcervical region bilaterally. The patient underwent surgical intervention under general anesthesia. A left pre-auricular bayonet-shaped incision was performed. The setting of a subcutaneous free flap was made by blunt dissection and subsequently the superficial musculo-aponeurotic system (SMAS) advancement flap was prepared. A total parotidectomy was performed with an en bloc removal of both masses and with preservation of the integrity of all facial nerve branches. A surgical drain was positioned and the SMAS flap was sutured in a tent fashion with the intention to fill the parotid bed, finally cutaneous suture was performed. The surgically removed tissue was sent to the laboratory for definitive histopathologic analysis. Post-surgical prescriptions included antibiotic therapy with amoxicillin and clavulanic acid (2,2 g every eight hours for five days), betamethasone (4 mg e.v. every twelve hours for three days) and paracetamol as needed for post-operative pain. No major neither minor complication were recorded. The histological examination confirmed the preoperative diagnosis of Warthin's tumor of both neo-formations.

\section{Case 2}

A 62-year-old man was admitted to the maxillofacial surgery department of our hospital for the presence of a painless swelling, located in the right parotid region. The absence of tenderness did not arouse alarm in the patient, who decided to seek medical advice only after 2 years from the moment in which the mass was noted for the first time. Furthermore, the patient reported an acceleration of growth rate in the last few months. At the anamnesis, the patient reported smoking habit lasting 40 years, amounting to 25 cigarettes per day, and an alcohol consumption of about 3 glasses/day. No other noteworthy information was referred. On physical examination the mass appeared as a hard consistency 
swelling, non-tender and mobile on superficial cutaneous plan that showed no other visible alteration on inspection. During the physical exam a second mass, with smaller size and not previously noted by the patient was found in correspondence of left parotid region. A computerized tomography scan was prescribed with and without contrast enhancement. The imaging studies confirmed the presence of two nodular masses with uneven consistence, localized in correspondence of parotid lower poles bilaterally. The neoformation of the right parotid was of $32 \mathrm{~mm}$, the previously unknown neoformation present on the left gland had a diameter of $17 \mathrm{~mm}$. CT scan ruled out the contextual presence of lymph nodes with increasing sizes other pathological pattern (Figs. 3, 4). The patient underwent to surgical ex-
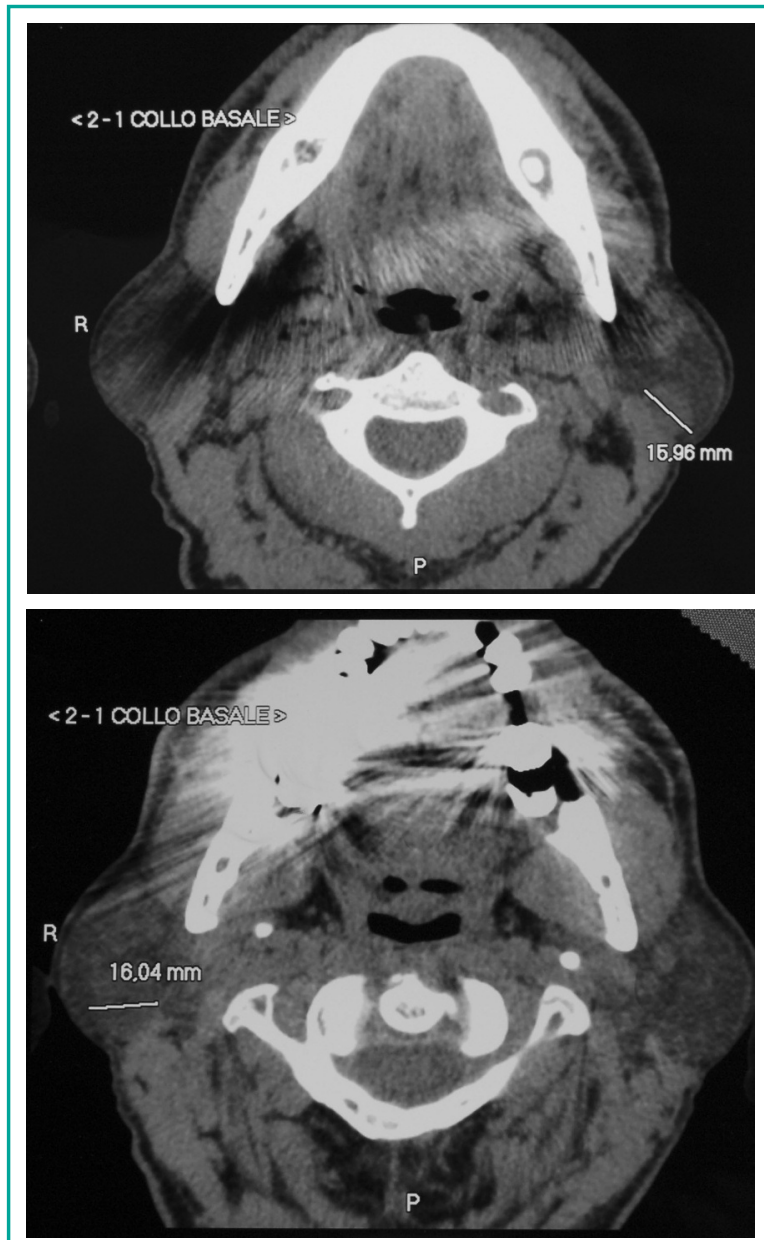

Figures 3, 4 - Preoperative CT view of bilateral parotids gland tumors. cision of the two masses under general anesthesia. Two bayonet-shaped pre-auricular incisions were performed bilaterally, with preparation of SMAS advancement flaps. Later, total parotidectomy was performed on both sides, with preservation of facial nerve branches, followed by SMAS flaps positioning. The intervention was concluded with surgical drains placement and skin suturing. No complications were recorded in the postoperative period. Excised material was sent to the pathology department that proved the diagnosis of bilateral Warthin's tumor.

\section{Discussion}

Warthin's tumor is a benign neoplasm of the major salivary glands. It was described for the first time by Hildebrand in 1895 , but the author that above any other contributed to the description of this lesion is Aldred Scott Warthin, the pathologist who gave the name to this entity $(9,10)$. Salivary glands tumors represent the $3 \%$ of all head and neck tumors, with predilection for the parotid gland (11). Pleomorphic Adenoma (PA) is the most common benign neoplasm, accounting for a $70 \%$ of all parotid masses, while Warthin's tumor is the second most common lesion, representing almost 6$10 \%$ of all salivary glands tumors $(1,2)$. In the past decades it has been known with many different names referring to its histological characteristics, including papillary cystadenoma lymphomatosum, cystadenolymphoma and adenolymphoma. Warthin's tumor is usually the preferred name used in order to avoid confusion with malignant lymphoid neoplasms (12). It predominantly arises in the 6th and 7th decade but it can be virtually diagnosed at any age with a range of 2,5-92 years $(3,4)$. There is a strong association with cigarette smoking, and the frequency of bilateral lesions directly correlates with the amount of nicotine intake (5, 13-16). In the past decades sex incidence was definitely higher in male gender, although recent studies have confirmed the increasing incidence among female sex that reduced M:F 
ratio from 10:1 to an almost equal rapport. The spreading of smoking habit among women could explain this relevant changing in sex incidence $(1,4,14-16)$. It is almost exclusively located in the superficial parotid gland, with a predilection for the inferior lobe (tail), only in $10 \%$ of patients it is found in the deep lobe. Occasionally it arises in the periparotid lymph nodes $(17,18)$. Warthin's tumor is multifocal in $12 \%$ of cases while bilateral lesion occurs in only $6 \%$ of patients (19). This tumor ordinarily presents as a slow-growing mass with an average size of $4 \mathrm{~cm}$ however, untreated old lesions can reach $10 \mathrm{~cm}$ or more in diameter (20). Clinically it appears as a limited oval mass frequently placed close to the angle of mandible, it is normally asymptomatic although in rare cases patients present discomfort, otalgia or deafness. Warthin's tumor is grossly delimited by a thin fibrous capsule; macroscopically it is composed of cysts containing an amorphous mucoid substance and solid areas. Microscopic pattern of this lesion is characteristic and absolute pathognomonic. Cystic spaces are bounded by a double-layer oncocytic epithelium. Luminal layer consists of columnar cells with finely granular cytoplasm (due to the high concentration of mitochondria) and nuclear palisading. Inner layer is composed by a floor of small cuboidal oncocytic elements (21). Small papillary infoldings originate from epithelium and projects into luminal spaces. Solid stromal component is made up of reactive lymphoid tissue with germinal centre formation, macrophages and plasma cells may also be found (22). Seifert et al. described four histological subtypes according to the epithelial/stromal prevalence (Tab. 1) (23). In this variant the classic oncocytic epithelium and the lymphomatous stroma are partially replaced by squamous metaplasia. Hemorrhagic and necrotizing areas are also present and could lead to erroneous diagnosis of squamous or mucoepidermoid carcinoma. This rare form, that is thought to be the consequence of traumatic events, is found in almost $6 \%$ of all Warthin's tumors. The increasing frequency of this type is probably ascribable to the raising use of diagnostic fine-needle aspiration (24, 25). Various theories about its histogenesis have been proposed, two of them are most commonly agreed. The first theory asserts that Warthin's tumor could be an atypical parotid adenoma in which an inflammatory response has caused an extensive lymphocytic infiltration $(26,27)$. The second theory, more absorbing, ascribes to the embryogenesis processes the origins of this disease. The crucial event would be the entrapment of salivary ductal cells in embryonic lymphocytic-rich tissues. Salivary gland cells precursor, derived from oral mucosa epithelium would take contact with parotid lymph nodes, these could later penetrate into parotid parenchyma to form intraparotid lymph nodes, this process is referred to the late encapsulation of the gland. This hypothesis puts Warthin's tumor near to lateral cervical cysts, though to origin from heterotopic inclusion of tonsillar tissue into cervical lymph nodes. It can also explain the relatively frequency of localization of Warthin's tumor out of the parotid, in cervical lymph nodes or

Table 1 - Histological subclassification of cystoadenoma by Seifert G, Bull HG, Donath K (Ref. 23).

\section{HISTOLOGICAL TYPE DESCRIPTION}

TYPICAL TYPE Most common form in which Epithelium/Stroma ratio is approximately equal

STROMA-POOR TYPE Epithelial component $>70 \%$

STROMA-RICH TYPE Stromal component $>70 \%$

METAPLASTIC TYPE In this variant, the classic oncocytic epithelium and the lymphomatous stroma are partially

replaced by squamous metaplasia. Hemorrhagic and necrotizing areas are also present 
sub-mandibular gland. The largest parts of lymph nodes included into the parotid gland are located in the superficial posterior lobe that explains the almost exclusive localization of the tumoral mass. These theories don't explain the possibility of tumor localization in lower neck or mediastinum, but Young and Scotfield suggested a defective closure of the sinus of His as a possible way for salivary gland cells to reach caudal regions of the neck. In both theories lymphocytic component is seen not derived from a primary cellular proliferation, rather as a reactive and grow-limiting phenomena against epithelial cell proliferation in the contest of a lymphoid tissue. As a support of all that, molecular studies on $\mathrm{X}$ chromosome by Honda et al. confirmed the polyclonal nature of lymphocytic cells whose proliferation would be to consider hyperplastic and not neoplastic. Diagnostic hypothesis can be made considering clinical and imaging studies features, but definitive diagnosis is ultimately based on histo-pathological characteristics. Useful imaging studies comprise Ultrasonography, MRI and TC. It is demonstrated that Warthin's tumor is able to capture and concentrate $99 \mathrm{~m} \mathrm{Tc}$ pertechnetate, and is therefore visualized as hot spots during scintigraphy examination. However, scintigraphy is not a routine diagnostic method for this tumor since studies proved ultrasonography to be superior (28). An useful tool for diagnosis and pre-operative planning is FNAC (Fine Needle Aspiration Cytology) that in a recent trial showed to have a sensitivity of $90.4 \%$ and a positive prediction value (PPV) of $98.1 \%$ (29). These results prove that sensitivity of FNAC could be higher than that reported by other series (30, 31). Only peculiar and atypical types of Warthin's tumor could result difficult to diagnose on cytological examination. This technique is only virtually risk free, in fact in some cases FNAC was thought to be responsible for intra-lesion traumatic hemorrhage that could switch a classical histology to the metaplastic subtype. The increasing frequency of lesions with metaplastic features is possibly caused by the spreading use of FNAC method. The surgi- cal technique most frequently used in the study groups we examined is the partial parotidectomy which seems to guarantee a good aesthetic and functional result, with this technique the risk to interfere with facial nerve anatomy and function is virtually null. Recent studies have also suggested the simple enucleation of the tumor mass. We believe that total parotidectomy should not be underrated, especially in the two cases we described. Although it is true that the latter results in a manipulation of the facial nerve, in our opinion its recourse is widely justified. In fact Warthin's tumor represents the salivary benign disease that most often can have features of multifocality and multilaterality (both synchronous and metachronous) and a large part of recurrences could be attributed to non-radical nature of superficial parotidectomy. Moreover, total parotidectomy has not substantial alternatives in the case of localization in the deep portion of the gland or tumor mass with remarkable dimensions. The complications of surgery are rare and usually limited to: hematoma, seroma, temporary paralysis of the facial nerve and Frey's syndrome. There is no uniformity of opinion about the follow-up; some authors do not consider it necessary, while others validate it for the possibility of recurrence and association between Warthin's tumor and other benign tumors of salivary glands. In this article we described two cases of Warthin's tumor in our opinion very interesting for their distinguishing characteristics. Although it is true that this tumor represents among major salivary glands neoplasms the second according to frequency, the chance of dealing with cases of multifocality or bilaterality is certainly not a common occurrence. In fact, we found only a few similar examples during the study of actual and past scientific literature. The aspect that was most influenced by the peculiarities of our two cases has been the therapeutic approach. The recent proved non-neoplastic nature of this entity and the tendency of surgical practice to avoid excessive invasiveness, has led to propose for most patients superficial surgical approach and for elected cases exclusively enucleation treat- 
ment. In the cases we handled the demonstrated tendency of these lesions to have multiple localizations, made us lean towards a more radical intervention. In support of this we can describe some justifying elements, and two of them are particularly relevant. The first one is the possibility of recurrence due to the partial radicality of superficial excision. The second one, strictly related to the former is the possibility of malignant degeneration that may be greater in cases that show since the beginning, multiple localizations feature. For this reason, the authors recommend to the patients periodic follow-up visits.

\section{References}

1. Eveson JW, Cawson RA. Salivary gland tumors: a review of 2410 cases with particular reference to histologic types, site, age and sex distribution. J Pathol. 1985;146:51-8.

2. Silva SJ, Morais S, Aguiar ASF, Lemos VCT, Fabiano P, Loyola AM. Clinic-epidemiologic study of 183 cases of salivary gland tumors, based on WHO's Classification 1991. Rev Bras Otorinolaringol. 1998; 64:38794.

3. Teymoortash A, Krasnewicz Y, Werner JA. Clinical features of cystadenolymphoma (Warthin's tumor) of the parotid gland: a retrospective comparative study of 96 cases. Oral Oncol. 2006;42:569-573.

4. Ellis GL, Auclair PL. Warthin's tumor (papillary cystadenoma lymphomatosum). In: Atlas of Tumor Pathology: Tumors of the Salivary Glands. 3rd series, fascicle 17. Washington DC: Armed Forces Institute of Pathology. 1996:68-79.

5. Klussmann JP, Wittekindt C, Preuss SF, Al Attab A, Schroeder U, Guntinas-Lichius O. High risk for bilateral warthin tumour in heavy smokers-review of 185 cases. Acta Otolaryngol. 2006;126(11):1213-1217.

6. Yoo G, Eisele D, Askin F, Driben J, Johns M. Warthin's tumor: a 40-year experience at the Johns Hopkins Hospital. Laryngoscope. 1994;104:799-803.

7. Lamelas J, Terry JH Jr, Alfonso AE. Warthin's tumor: multicentricity and increasing incidence in women. Am J Surg. 1987; 154:347-51.

8. Monk JS, Church JS. Warthin's tumor: a high incidence and no sex predominance in central Pennsylvania. Arch Otolaryngol Head Neck Surg. 1992; 118(5):477-478.

9. Hildebrand O. Die angeborene epitheliale Cysten und Fisteln des Halses. Arch Klin Chir. 1895;49:16792.
10. Warthin AS. Papillary cystadenoma lymphomatosum. Cancer Res. 1929;13: 16-25.

11. Ellis GL, Auclair PL, Gnepp DR. Surgical pathology of the salivary glands. Philadelphia: W.B. Saunders Co; 1991. p. 165.

12. Ma J, Chan JKC, Chow CW, et al. Lymphadenoma: a report of three cases of an uncommon salivary gland neoplasm. Histopathology. 2002;41(4):250-259.

13. De Ru JA, Plantinga RF, Majoor MH, van Benthem PP, Slootweg PJ, Peeters PH, et al. Warthin's tumor and smoking. B-ENT. 2005;1:63-66.

14. Vories A, Ramirez S. Warthin's tumor and cigarette smoking. South Med J. 1997;90:416-8.

15. Pinkston JA, Cole P. Cigarette smoking and Warthin's tumor. Am J Epidemiol. 1996;144(2): 183-187.

16. Kotwall CA. Smoking as an etiologic factor in the development of Warthin's tumor of the parotid gland. Am J Surg. 1992;164(6):646-647.

17. Gnepp DR, Brandwein MS, Henley JD. Salivary and lacrimal glands. In: Gnepp DR, eds. Diagnostic Surgical Pathology of the Head and Neck. Philadelphia: WB Saunders, 2001:325-430.

18. Snyderman C, Johnson JT, Barnes EL. Extraparotid Warthin's tumor. Otolaryngol Head Neck Surg. 1986; 94(2):169-75.

19. Maiorano E, Lo Muzio L, Favia G, et al. Warthin's tumor: a study of 78 cases with emphasis on bilaterality, multifocality and association with other malignancies. Oral Oncol. 2002;38(1):35-40.

20. White RR, Arm RN, Randall P. A large Warthin's tumor of the parotid: case report. Plast Reconstr Surg. 1978;61(3):452-454.

21. Eveson JW, Cawson RA. Warthin's tumor (cystadenolymphoma) of salivary glands. A clinicopathologic investigation of 278 cases. Oral Surg Oral Med Oral Pathol. 1986;61(3):256-262.

22. Simpson RHW, Eveson JW. Warthin's tumor. In: Barnes L, Eveson JW, Reichart P, eds. World Health Organization Classification of Tumors: Pathology and Genetics of Head and Neck Tumors. Lyon: IARC Press, 2005;263-265.

23. Seifert G, Bull HG, Donath K. Histological subclassification of the cystadenoma of the parotid gland: analysis of 275 cases. Virchows Archiv A Pathol Anat Histol. 1980;388(1):13-38.

24. Di Palma S, Simpson RHW, Skálová A, Michal M. Metaplastic (infarcted) Warthin's tumor of the parotid gland: a possible consequence of fine needle aspiration biopsy. Histopathology. 1999;35:432-438.

25. Eveson JW, Cawson RA. Infarcted ('infected') adenolymphomas. A clinicopathological study of 20 cases. Clin Otolaryngol. 1989;14:205-210.

26. Arida M, Barnes EL, Hunt JL. Molecular assessment of allelic loss in Warthin tumors. Mod Pathol 2005; 18(7):964-8.

27. Teymoortash A, Werner JA. Tissue that has lost its track: Warthin's tumour. Virchows Arch. 2005;446:585-588. 
28. Motoori K, Ueda T, Uchida Y, et al. Identification of Warthin tumor: magnetic resonance imaging versus salivary scintigraphy with technetium-99m pertechnetate. J Comput Assist Tomogr. 2005;29(4):506-512.

29. Viguer JM, Vicandi B, Jimenez-Heffernan JA, LopezFerrer P, Gonzalez-Peramato P, Castillo C. Role of fine needle aspiration cytology in the diagnosis and management of Warthin's tumour of the salivary glands. Cytopathology. 2010;21:164-169.

30. Ballo MS, Shin HJC, Sneige N. Sources of diagnostic error in the fine-needle aspiration diagnosis of Warthin's tumor and clues to a correct diagnosis. Diagn Cytopathol. 1997; 17:230-234.
31. Klijanienko J, Viehl P. Fine needle sampling of salivary gland lesions. II. Cytology and histology correlation of 71 cases of Warthin's tumor. Diagn Cytopathol. 1997;16:221-5.

\section{Correspondence to:}

Bruno Lorè, MD

University of Rome "Tor Vergata"

Department of Oral and Maxillo-Facial Surgery Viale Oxford 81 - 00133 Rome, Italy

Phone: +39 06209001 - Fax: +39 0620902742

E-mail: bruno.lore@uniroma2.it 